\title{
Laboratory Investigation of Energy Propagation and Scattering Characteristics in Cylindrical Rock Specimens
}

\author{
Lu Chen (iD, Lan Qiao, Jianming Yang, and Qingwen Li iD \\ Department of Civil Engineering, University of Science and Technology Beijing, Beijing 100083, China \\ Correspondence should be addressed to Qingwen Li; qingwenli@ustb.edu.cn
}

Received 9 May 2018; Revised 17 July 2018; Accepted 7 August 2018; Published 24 September 2018

Academic Editor: Wei Wu

Copyright (c) 2018 Lu Chen et al. This is an open access article distributed under the Creative Commons Attribution License, which permits unrestricted use, distribution, and reproduction in any medium, provided the original work is properly cited.

\begin{abstract}
Deep mining involves complex geological environments. Moreover, along with strong disturbance, rockbursts and other severe dynamic hazards can occur frequently. Energy theory is widely regarded as the most appropriate method for understanding the mechanism of deep dynamic problems. When modeling dynamic disasters, energy theory includes the energy storage, energy accumulation, and energy transfer. To study the energy transfer characteristics in rock, a series of split-Hopkinson pressure bar (SHPB) impact tests were conducted with long granite specimens ( $400 \mathrm{~mm}$ in length and $50 \mathrm{~mm}$ in diameter) and modified incidence bars (having the same cross-sectional area but different shapes). The test results indicate that the impact energy decays exponentially with an energy attenuation coefficient of -0.42 . For the scattering characteristics of energy in the rock, the scattering distance is found to be approximately three times the specimen diameter, which is very similar to Saint-Venant's principle in elastic mechanics.
\end{abstract}

\section{Introduction}

Deep mining is gradually becoming more prevalent owing to the lack of shallow mineral resources. In the deep underground, the geological environment becomes complex, particularly the high geostress. Under these circumstances, rockbursts and other dynamic disasters are quite severe and are frequently induced by strong disturbances. Recently, rockbursts have become the biggest threat in deep mining and have attracted wide concern. Shan and Yan investigated the locations and modes of rockbursts and evaluated methods to reduce their effect during the excavation of deep tunnels for the Jinping II Hydropower Station [1]. He and Dou established a gradient principle for rockbursts induced by horizontal stress in coal mining and proposed a criterion for layer dislocation rockbursts induced by horizontal stress [2]. Zhou et al. analyzed the mechanism of rockbursts induced by structural planes in deep tunnels and classified the rockbursts into three types [3]. Dou et al. studied the monitoring, forecasting, and prevention of rockbursts in underground coal mining in China [4]. Chen et al. investigated the effect of temperature on rockbursts in the hard rock of deep-buried tunnels and determined that the likelihood of a rockburst increased as the temperature increased [5]. Cai et al. conducted a quantitative analysis of seismic velocity tomography for rockburst hazard assessment [6].

A large number of studies have verified that energy theory is the most appropriate approach to describe the mechanism of dynamic disasters [7]. Thus, an increasing number of researchers have started to investigate rockbursts from an energy perspective. Jiang et al. employed a new energy index to investigate rockburst characteristics and their numerical simulation [8]. Kornowski and Kurzeja predicted rockburst probability using the given seismic energy and other factors defined by the expert method of hazard evaluation [9]. Sirait et al. used the energy balance and induced stress method to predict the rockburst of a cut and fill mine [10]. Feng et al. analyzed the fractal behavior of microseismic energy associated with immediate rockbursts in deep hard rock tunnels [11]. Wang et al. studied the characteristic energy factor of a deep rock mass under weak disturbance [12].

For considering dynamic disasters, energy theory includes the energy storage, energy accumulation, and energy 
transfer. Many studies have focused on stored energy in the rock. Hamiel et al. investigated the nonlinear behavior of damaged materials and conducted a large number of calculations and simulations of their elastic strain energy [13]. $\mathrm{He}$ et al. divided rockbursts into impact-induced bursts and strain bursts according to their stress path, and uniaxial compressive tests were performed to analyze the stored strain energy in strain bursts [14]. Li et al. carried out uniaxial compression tests at nine strain rates (ranging from $10^{-5}$ to $10^{-1} \mathrm{~s}^{-1}$ ) and determined the increase of strain energy with the strain rate. The test results also showed that the elastic strain energy stored before reaching the peak led to brittle failure of the specimens [15]. Weng et al. used the energy index and strain energy density to analyze the energy accumulation and dissipation characteristics during the failure process of rock [16]. Zhou and Yang employed the strain energy method to investigate the dynamic damage localization features in a crack-weakened rock mass [17]. As discussed above, many studies have focused on strain energy storage, energy accumulation, and dissipation characteristics, but few have investigated energy transfer and propagation.

At present, Li et al. [18], Chen et al. [19, 20], Chai et al. [21], and Shao and Pyrak-Nolte [22] have studied stress wave propagation characteristics in rock. By employing a testing method for stress wave propagation, the energy propagation and scattering characteristics of rock specimens can be studied through laboratory tests. In this study, a series of split-Hopkinson pressure bar (SHPB) impact tests were conducted with long granite specimens $(400 \mathrm{~mm}$ in length and $50 \mathrm{~mm}$ in diameter) and modified incidence bars (having the same cross-sectional area but different shapes). The results show that the impact energy exhibits an exponential decay, and the energy attenuation coefficient is -0.42 . For the energy-scattering characteristics of rock, the scattering distance is approximately three times the rock diameter, which is very similar to Saint-Venant's principle in elastic mechanics. Using numerical simulations, the test results are displayed and verified. These experimental results and numerical analyses can provide scientific guidance for in situ engineering projects.

\section{Laboratory Test of Energy Propagation}

2.1. Experimental Setup and Specimens. One-dimensional dynamic impact tests were conducted using an SHPB system (Figure 1) to determine the propagation and attenuation characteristics of the impact energy, as this is regarded as the most efficient approach for studying the dynamic characteristics of rocks.

To analyze the propagation and attenuation characteristics accurately, the rock specimens used must be sufficiently long. Here, the rock specimens were obtained from the Sanshandao gold mine in China. To reduce the influence of specimen heterogeneity on the results, all the cylindrical specimens were cut from a single block of deep granite rock without any visible cracks. The dimensions of the specimens are $400 \mathrm{~mm}$ in length and $50 \mathrm{~mm}$ in diameter. The rock block and rock specimens are shown in Figure 2.

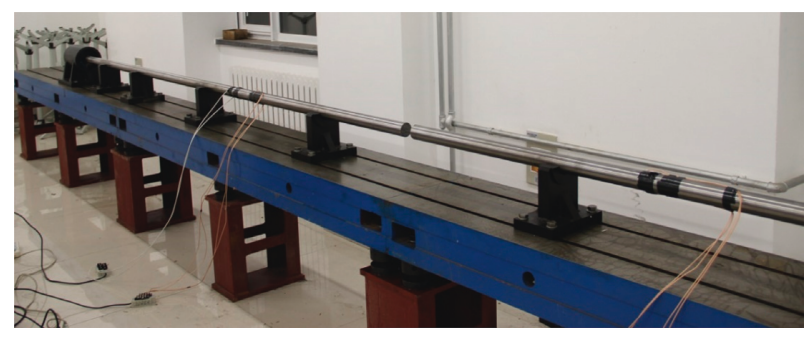

FIGURE 1: SHPB testing system.

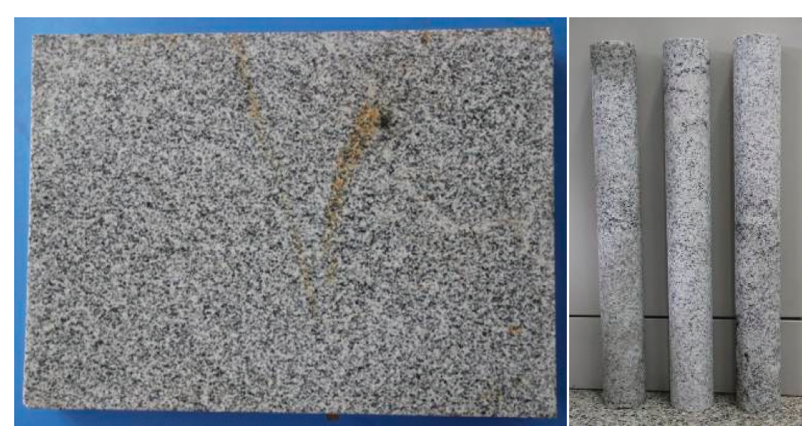

FIGURE 2: Whole rock block and specimens cut for the experiments.

For unconventional SHPB tests, due to the stress disequilibrium, traditional principles are not applicable. Scholars have recognized this problem and proposed some estimating methods [23] and monitoring approaches [24]. In tests, strain gauges were pasted on both specimens and bars. Based on the diameter of the rock specimen $(D)$, strain gauges were pasted on the specimens at distances of $50 \mathrm{~mm}$, $100 \mathrm{~mm}, 150 \mathrm{~mm}, 250 \mathrm{~mm}$, and $350 \mathrm{~mm}(1 D, 2 D, 3 D, 5 D$, and $7 D$ ) from the impacted end, as shown in Figure 3. An ultradynamic acquisition instrument was used to directly monitor the dynamic strains of specimens during the tests.

The shape and duration of the incident wave is one of the determinants of energy attenuation and scattering characteristics. To obtain stable sinusoidal dynamic strain curves and eliminate the dispersion effect, a fusiform bullet was used in the tests, as shown in Figure 4. A typical incident wave is shown in Figure 5.

As shown in the conceptual sketch in Figure 3, the transmitted bar and damper are indispensable components to prevent the reflected wave from affecting the test results. In this study, the length of the transmitted bar is $2 \mathrm{~m}$. According to the actual measurements, for a wave velocity $c=5189 \mathrm{~m} / \mathrm{s}$, the time of the transmitted wave to propagate to the damper and then reflect back to the specimen is approximately $0.00077 \mathrm{~s}$. Therefore, if the duration of the incident wave is less than $0.00077 \mathrm{~s}$, there will be no reflection from the transmitted bar affecting the test results. The typical incident wave is shown in Figure 5, and the duration of the incident wave is approximately $0.00044 \mathrm{~s}$.

\subsection{Analysis of Energy Propagation along the Axial Direction.}

For brittle failure of rock materials such as granite, there must be a damage threshold under impact loading. Li investigated the relationship between the minimum strain rate 


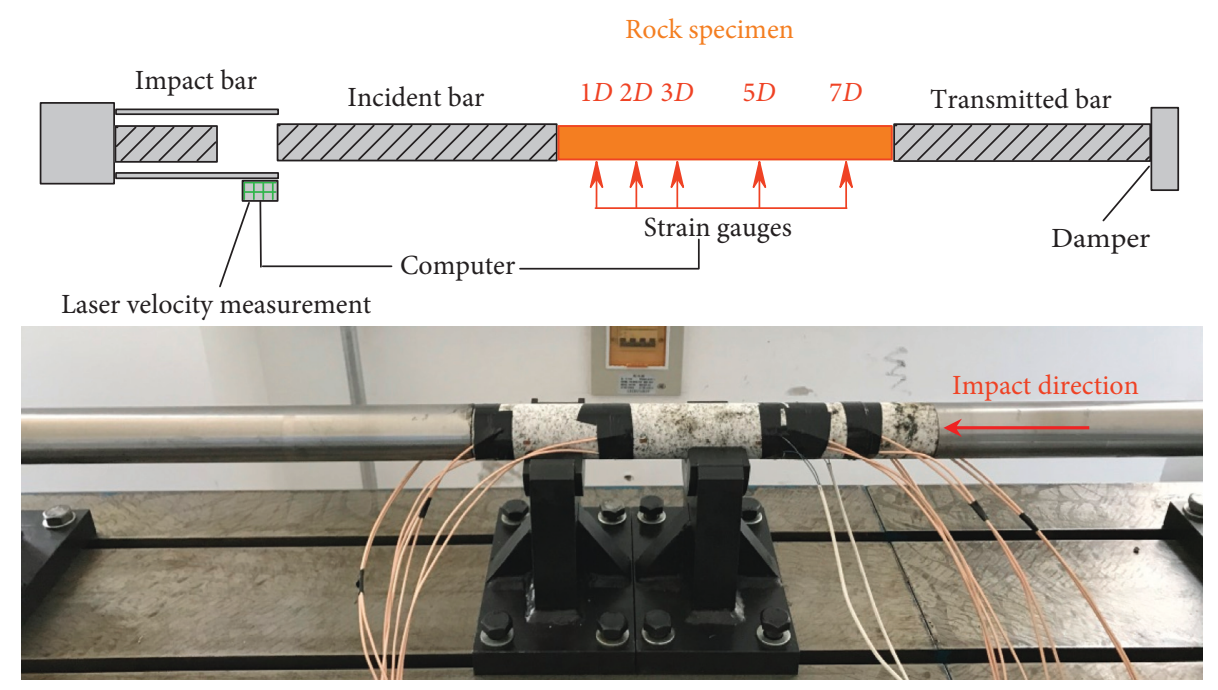

FIGURE 3: Dynamic strain monitoring in the tests.

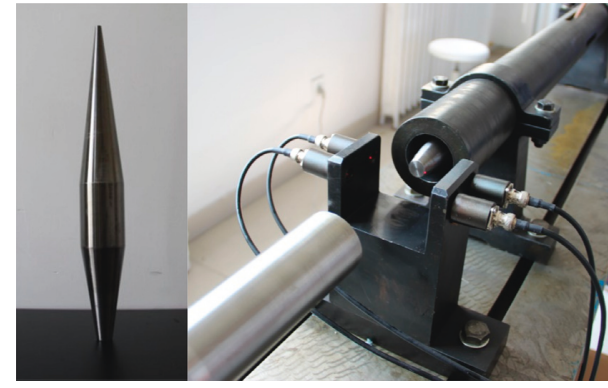

FIGURE 4: Fusiform bullet used in the tests.

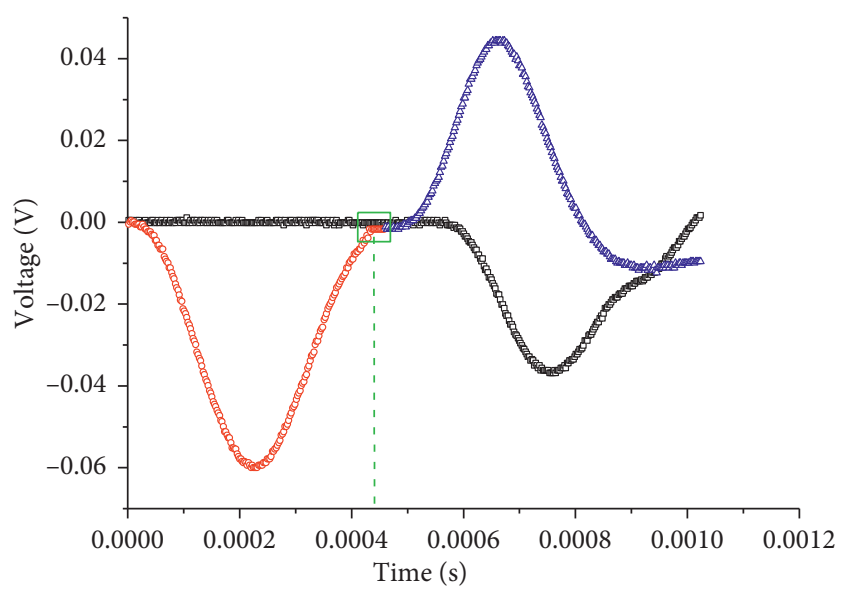

$\square$ Transmitted wave

o Incident wave

$\triangle$ Reflected wave

FIGURE 5: Typical incident wave shape and duration.

and bar diameter using the Holmquist-Johnson-Cook (HJC) model with the LS-DYNA software [25]. The fitted curves describing the relationship between the minimum strain rate and bar diameter are shown in Figure 6.

In this study, the diameter of the bar is $50 \mathrm{~mm}$, and thus, the strain rate at the damage threshold is between $100 \mathrm{~s}^{-1}$

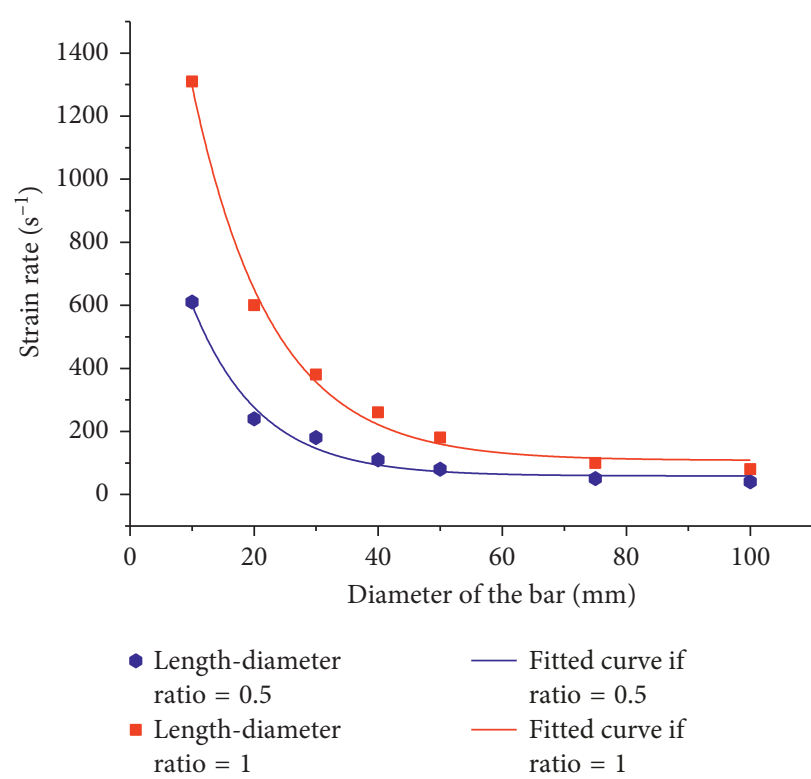

FIGURE 6: Fitted curves representing the relationship between the minimum strain rate and bar diameter.

and $150 \mathrm{~s}^{-1}$ for the rock specimens. To eliminate plastic energy loss, the granite specimen should be kept in the linearly elastic state; hence, the impact velocity in the experiments is controlled at $4-6 \mathrm{~m} / \mathrm{s}$. After 12 sets of impact energy tests, the attenuation characteristics of the dynamic strain (maximum strain value) under different impact velocities were obtained, as shown in Figure 7.

In the elastic state, the energy in the specimen can be calculated using the following equation:

$$
U_{\mathrm{e}}=\frac{1}{2} E \varepsilon^{2},
$$

where $U_{\mathrm{e}}$ is the dynamic elastic energy, $E$ is the dynamic elastic modulus of the specimen, and $\varepsilon$ is the dynamic strain.

After performing this calculation, the propagation and attenuation characteristics of the impact energy along the 


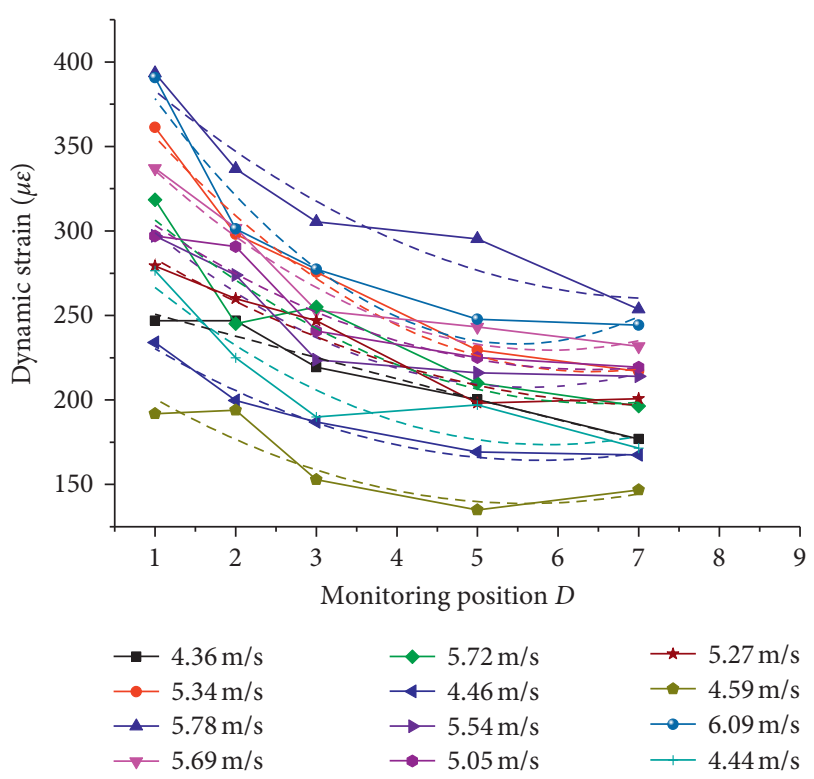

FIgURe 7: Dynamic strains under different impact velocities.

axial direction in the cylindrical specimens are fitted, as shown in Figure 8.

It can be seen that the impact energy decreases sharply at $1 D, 2 D$, and $3 D$. When the distance exceeds $3 D$, the impact energy levels off gradually. In other words, the impact energy initially attenuates dramatically, and the attenuation value can be as high as $40 \%$. However, as the distance continues to increase, the energy variation becomes more gradual. To describe this special characteristic of the elastic energy attenuation, the attenuation law was fitted.

After fitting, the energy attenuation law could be represented by a power function. The uniform expression is as follows:

$$
U_{\mathrm{e}}=A N^{-0.42},
$$

where $A$ is the fitting coefficient, $N$ is the monitoring position, and the exponent equal to -0.42 represents the average value of 12 fitted power functions.

The values of the fitting coefficient, $A$, are summarized in Table 1.

As Table 1 indicates, the fitting coefficient is approximately equal to the elastic energy at the $1 D$ position. Hence, to ensure that each parameter in the above expression has an explicit physical meaning and to consider the acceptable error, Equation (2) is rewritten as follows:

$$
U_{\mathrm{e}}=U_{1 D} N^{-0.42}
$$

Thus, the energy attenuation law for the rock is a power function based on the initial elastic energy and an exponent of -0.42 .

\section{Laboratory Tests of Energy Scattering}

3.1. Laboratory Testing Method for Energy Scattering. Research has indicated that energy scattering is related to the impact mode and propagation distance. To determine the

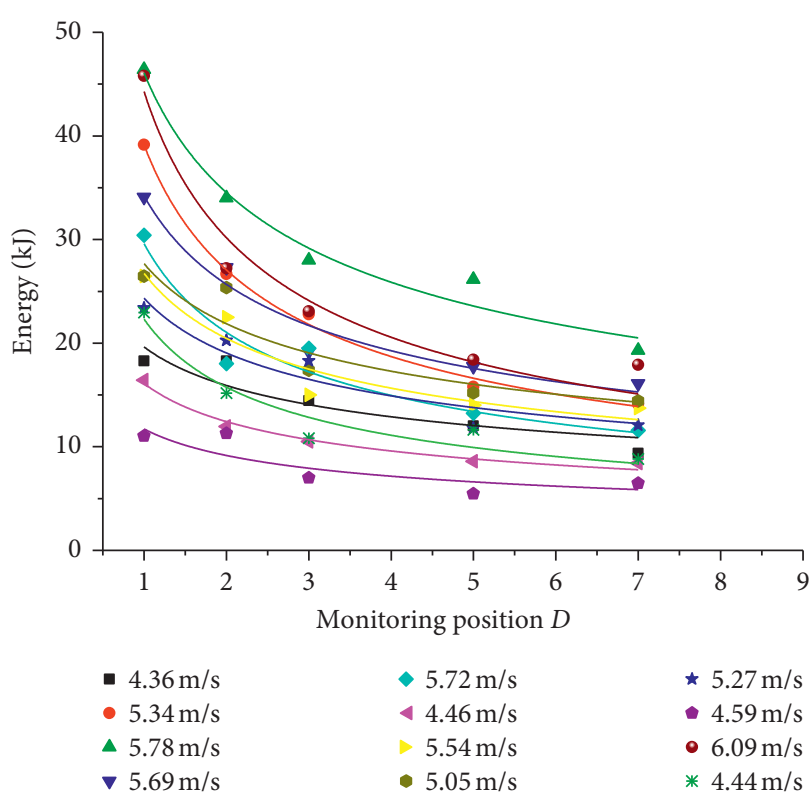

FIgURE 8: Energy attenuation law under different impact velocities.

energy-scattering characteristics, a series of modified SHPB tests were carried out using incident bars with ends having the same cross-sectional area but different shapes, as shown in Figure 9. The outer diameters of the modified ends are $25 \mathrm{~mm}$, $30 \mathrm{~mm}, 35 \mathrm{~mm}$, and $40 \mathrm{~mm}$ (designated $\Phi 1, \Phi 2, \Phi 3$, and $\Phi 4$ ), corresponding to $5 / 10,6 / 10,7 / 10$, and $8 / 10$ the diameter of the original incident bar (Ф5) in the SHPB system, respectively. The dimensions of the modified ends are listed in Table 2.

3.2. Analysis of Energy Scattering along the Radial Direction. By changing the position of action of the impact energy, the energy-scattering characteristics can be confirmed. For each modified end, tests were carried out four times under an impact velocity of $4-6 \mathrm{~m} / \mathrm{s}$. The dynamic strains at the $1 D, 2 D$, $3 D, 5 D$, and $7 D$ locations were monitored. The calculated energy for the different ends is shown in Figure 10.

It can be observed that there are obvious differences in the trends from $1 D$ to $3 D$ with the different incident bars. That is to say, the impact energy scatters significantly from $1 D$ to $3 D$ (particularly at $1 D$ to $2 D$ ), and the scattering characteristics are closely related to the impact modes. However, as the distance continues to increase, the energy variations are basically the same, which indicates that the different-shaped ends have little influence on the energy scattering at longer distances. This energy-scattering characteristic is very similar to Saint-Venant's principle in elastic mechanics. Therefore, it can also be concluded that the impact energy with different action positions can only produce different effects before the distance of $3 D$. Once the distance exceeds $3 D$, the action modes have little effect on the energy.

\section{Numerical Simulations of SHPB Tests}

With the development of numerical simulation techniques, some experimental results can be demonstrated visually. 
Table 1: Fitting coefficient, $A$, and elastic energy at the $1 D$ position.

\begin{tabular}{|c|c|c|c|c|c|c|c|c|c|c|c|c|}
\hline$v_{D}$ & 4.36 & 5.34 & 5.78 & 5.69 & 5.72 & 4.46 & 5.54 & 5.05 & 5.27 & 4.59 & 6.09 & 4.44 \\
\hline$A$ & 19.63 & 39.14 & 46.07 & 34.2 & 29.6 & 16.1 & 26.7 & 27.7 & 24.3 & 11.7 & 44.3 & 22.3 \\
\hline$U_{1 D}$ & 18.3 & 39.1 & 46.4 & 34.1 & 30.4 & 16.4 & 26.5 & 26.5 & 23.4 & 11 & 45.8 & 22.9 \\
\hline
\end{tabular}

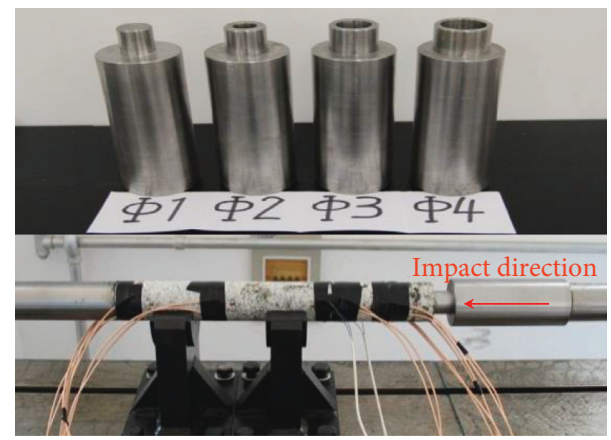

FIGURE 9: Modified ends of the incident bar.

TABLE 2: Specifications of the modified ends in SHPB tests.

\begin{tabular}{|c|c|c|c|c|c|}
\hline Ends & $\Phi 1$ & $\Phi 2$ & $\Phi 3$ & $\Phi 4$ & $\Phi 5$ \\
\hline Outer diameter (mm) & 25 & 30 & 35 & 40 & 50 \\
\hline Inner diameter $(\mathrm{mm})$ & 0 & 16.6 & 24.5 & 31.23 & 0 \\
\hline Cross-sectional area $\left(\mathrm{mm}^{2}\right)$ & 490.625 & 490.625 & 490.625 & 490.625 & 1962.5 \\
\hline Length $(\mathrm{mm})$ & 25 & 25 & 25 & 25 & - \\
\hline
\end{tabular}

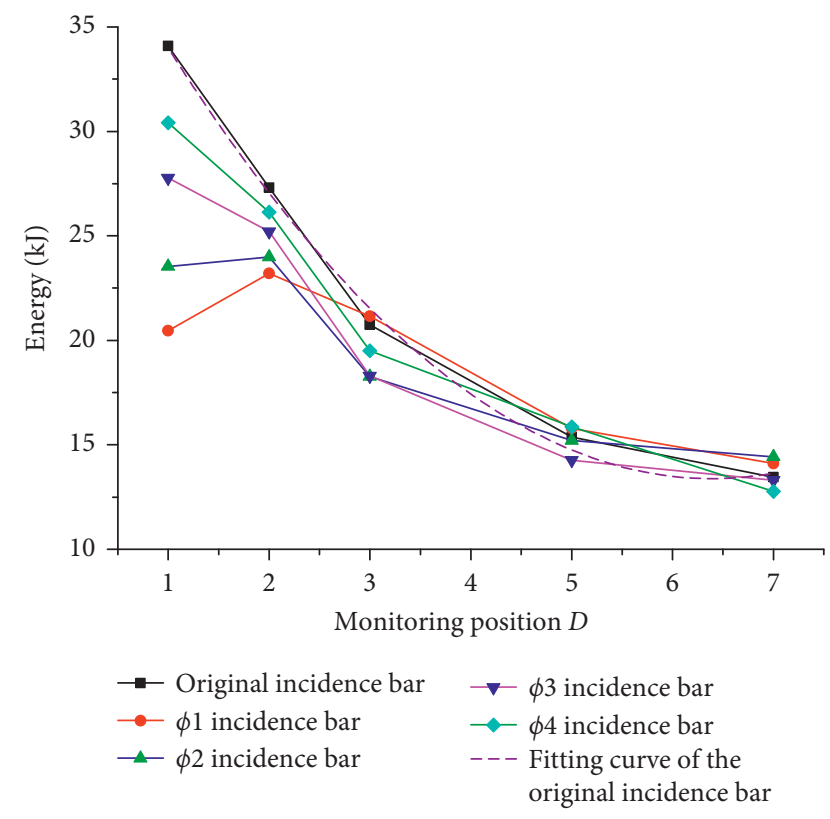

Figure 10: Energy scattering with different incidence bar ends.

Here, using the numerical simulation software LS-DYNA, the energy propagation and scattering process was simulated. The parameters and dimensions used in the numerical simulation are the same as those of the rock specimens used in the lab tests. Figure 11 shows the energy propagation process along the axial direction at different times. It can be clearly seen that the impact energy propagates and attenuates with time.

The energy-scattering characteristics can also be represented by the numerical simulations, as shown in Figure 12. It can be observed that, under different impact modes, the energy-scattering characteristics differ near the impact end; however, farther from the impact end (i.e., distances greater than $3 D$ ), the energy-scattering characteristics exhibit little difference. The numerical analysis results are thus consistent with the results of the tests.

\section{Conclusions}

In this study, a series of SHPB impact tests were conducted using long granite specimens and modified incidence bars to investigate the energy propagation and scattering characteristics in long cylindrical rock specimens. The main conclusions of this study are as follows.

Under impact, energy propagates and attenuates in the specimen along the axial direction. The experimental results suggest that the impact energy can be represented by a power function decay using the initial value and an energy attenuation coefficient of -0.42 .

The impact energy scatters at distances of $1 D-3 D$, and the scattering characteristics are closely related to the impact modes. However, at greater distances, the energy-scattering characteristics exhibit little difference. This energy-scattering 


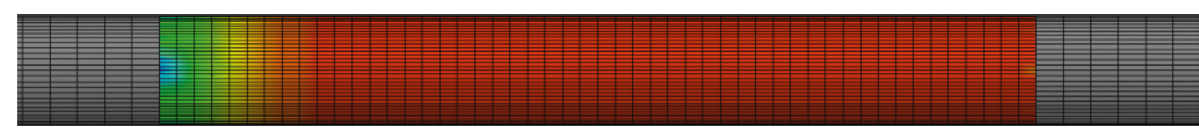

(a)

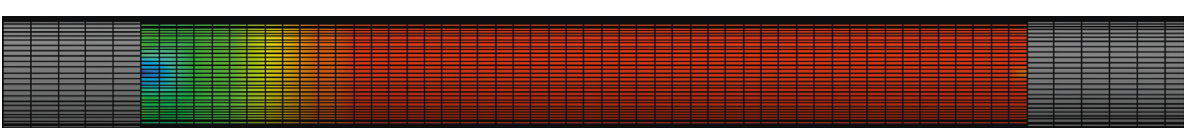

(b)

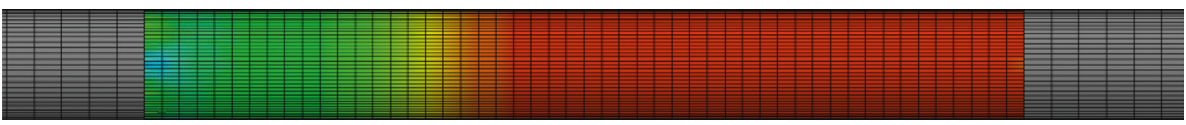

(c)

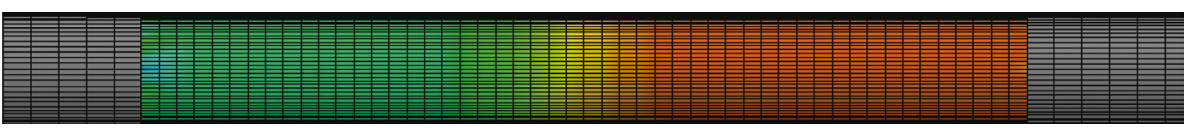

(d)

FIGURE 11: Energy propagation and attenuation in the numerical simulation results: (a) $0.558 \mathrm{~ms}$. (b) $0.570 \mathrm{~ms}$. (c) $0.600 \mathrm{~ms}$. (d) $0.624 \mathrm{~ms}$.

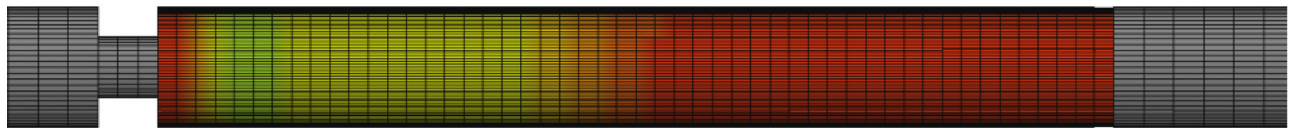

(a)

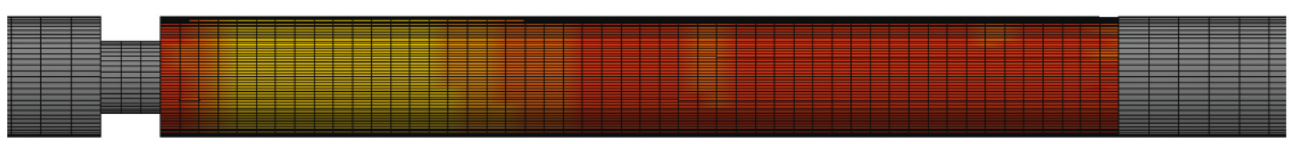

(b)

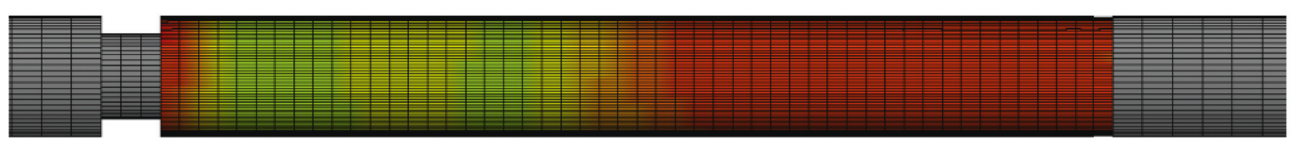

(c)

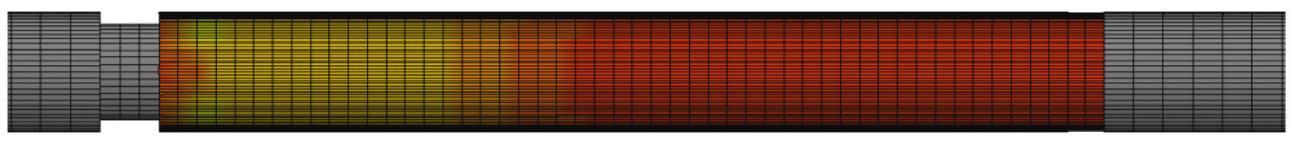

(d)

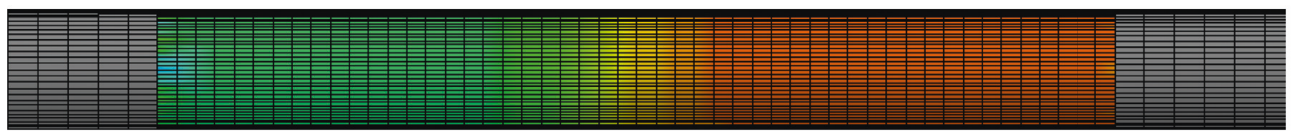

(e)
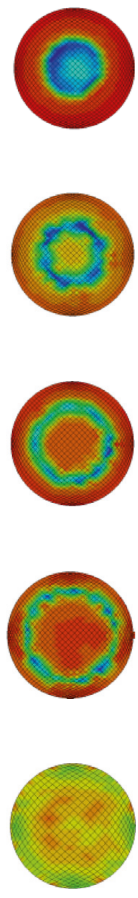

Figure 12: Energy scattering in the numerical simulations: (a)Ф1. (b)Ф2. (c)Ф3. (d)Ф4. (e)Ф5.

characteristic is similar to Saint-Venant's principle in elastic mechanics.

The energy propagation and scattering characteristics revealed by this study can be applied to the analysis of rockbursts using energy theory and are particularly relevant to the energy superposition problem caused by blasting or other excavations in deep mining, which can provide scientific guidance for in situ engineering projects.

\section{Data Availability}

The data used to support the findings of this study are available from the corresponding author upon request.

\section{Conflicts of Interest}

The authors declare that there are no conflicts of interest regarding the publication of this paper. 


\section{Acknowledgments}

This work was supported by the State Key Research Development Program of China (No. 2016YFC0600703) and the National Natural Science Foundation of China (Nos. 51704014 and 51674013).

\section{References}

[1] Z. G. Shan and P. Yan, "Management of rock bursts during excavation of the deep tunnels in Jinping II Hydropower Station," Bulletin of Engineering Geology and the Environment, vol. 69, no. 3, pp. 353-363, 2010.

[2] J. He and L. M. Dou, "Gradient principle of horizontal stress inducing rock burst in coal mine," Journal of Central South University, vol. 19, no. 10, pp. 2926-2932, 2012.

[3] H. Zhou, F. Z. Meng, C. Q. Zhang, D. W. Hu, F. J. Yang, and J. J. Lu, "Analysis of rockburst mechanisms induced by structural planes in deep tunnels," Bulletin of Engineering Geology and the Environment, vol. 74, no. 4, pp. 1435-1451, 2014.

[4] L. M. Dou, Z. L. Mu, Z. L. Li, A. Y. Cao, and S. Y. Gong, "Research progress of monitoring, forecasting, and prevention of rockburst in underground coal mining in China," International Journal of Coal Science \& Technology, vol. 1, no. 3, pp. 278-288, 2014.

[5] G. Q. Chen, T. B. Li, G. F. Zhang, H. Y. Yin, and H. Zhang, "Temperature effect of rock burst for hard rock in deep-buried tunnel," Natural Hazards, vol. 72, no. 2, pp. 915-926, 2014.

[6] W. Cai, L. M. Dou, S. Y. Gong, Z. L. Li, and S. S. Yuan, "Quantitative analysis of seismic velocity tomography in rock burst hazard assessment," Natural Hazards, vol. 75, no. 3, pp. 2453-2465, 2015.

[7] X. P. Zhou, "Triaxial compressive behavior of rock with mesoscopic heterogenous behavior: strain energy density factor approach," Theoretical and Applied Fracture Mechanics, vol. 45, no. 1, pp. 46-63, 2006.

[8] Q. Jiang, X. T. Feng, T. B. Xiang, and G. S Su, "Rockburst characteristics and numerical simulation based on a new energy index: a case study of a tunnel at 2,500 $\mathrm{m}$ depth," Bulletin of Engineering Geology and the Environment, vol. 69, no. 3, pp. 381-388, 2010.

[9] J. Kornowski and J. Kurzeja, "Prediction of rockburst probability given seismic energy and factors defined by the expert method of hazard evaluation (MRG)," Acta Geophysica, vol. 60, no. 2, pp. 472-486, 2012.

[10] B. Sirait, R. K. Wattimena, and N. P. Widodo, "Rockburst prediction of a cut and fill mine by using energy balance and induced stress," Procedia Earth and Planetary Science, vol. 6, pp. 426-434, 2013.

[11] X. T. Feng, Y. Yu, G. L. Feng, Y. X. Xiao, B. R. Chen, and Q. Jiang, "Fractal behaviour of the microseismic energy associated with immediate rockbursts in deep, hard rock tunnels," Tunnelling and Underground Space Technology, vol. 51, pp. 98-107, 2016.

[12] M. Y. Wang, J. Li, L. J. Ma, and H. X. Huang, "Study on the characteristic energy factor of the deep rock mass under weak disturbance," Rock Mechanics and Rock Engineering, vol. 49, no. 8, pp. 3165-3173, 2016.

[13] Y. Hamiel, V. Lyakhovsky, and Y. Ben, "The elastic strain energy of damaged solids with applications to non-linear deformation of crystalline rocks," Pure and Applied Geophysics, vol. 168, no. 12, pp. 2199-2210, 2011.
[14] M. C. He, H. M. Xia, X. N. Jia, W. L. Gong, F. Zhao, and K. Y. Liang, "Studies on classification, criteria and control of rockbursts," Journal of Rock Mechanics and Geotechnical Engineering, vol. 4, no. 2, pp. 97-114, 2012.

[15] Y. R. Li, D. Huang, and X. A. Li, "Strain rate dependency of coarse crystal marble under uniaxial compression: strength, deformation and strain energy," Rock Mechanics and Rock Engineering, vol. 47, no. 4, pp. 1153-1164, 2014.

[16] L. Weng, L. Q. Huang, A. Taheric, and X. B. Li, "Rockburst characteristics and numerical simulation based on a strain energy density index: a case study of a roadway in Linglong gold mine, China," Tunnelling and Underground Space Technology, vol. 69, pp. 223-232, 2017.

[17] X. P. Zhou and H. Q. Yang, "Dynamic damage localization in crack-weakened rock mass: strain energy density factor approach," Theoretical and Applied Fracture Mechanics, 2017, In press.

[18] J. C. Li, H. B. Li, and J. Zhao, "An improved equivalent viscoelastic medium method for wave propagation across layered rock masses," International Journal of Rock Mechanics \& Mining Sciences, vol. 73, pp. 62-69, 2015.

[19] X. Chen, J. C. Li, M. F. Cai, Y. Zou, and J. Zhao, "Experimental study on wave propagation across a rock joint with rough surface," Rock Mechanics and Rock Engineering, vol. 48, no. 6, pp. 2225-2234, 2015.

[20] X. Chen, J. C. Li, M. F. Cai, Y. Zou, and J. Zhao, "A further study on wave propagation across a single joint with different roughness," Rock Mechanics and Rock Engineering, vol. 49, no. 7, pp. 2701-2709, 2016.

[21] S. B. Chai, J. C. Li, Q. B. Zhang, H. B. Li, and N. N. Li, "Stress wave propagation across a rock mass with two non-parallel joints," Rock Mechanics and Rock Engineering, vol. 49, no. 7, pp. 4023-4032, 2016.

[22] S. Shao and L. J. Pyrak-Nolte, "Wave propagation in isotropic media with two orthogonal fracture sets," Rock Mechanics and Rock Engineering, vol. 49, no. 10, pp. 4033-4048, 2016.

[23] W. Wu, H. B. Li, and J. Zhao, "Dynamic responses of nonwelded and welded rock fractures and implications for P-wave attenuation in a rock mass," International Journal of Rock Mechanics \& Mining Sciences, vol. 77, pp. 174-181, 2015.

[24] L. Chen, Q. W. Li, J. M. Yang, and L. Qiao, "Laboratory testing on energy absorption of high-damping rubber in a new bolt for preventing rockburst in deep hard rock mass," Shock and Vibration, vol. 2018, Article ID 7214821, 12 pages, 2018.

[25] X. B. Li, Rock Dynamic Fundamentals and Applications, China Science Press, Beijing, China, 2014, in Chinese. 


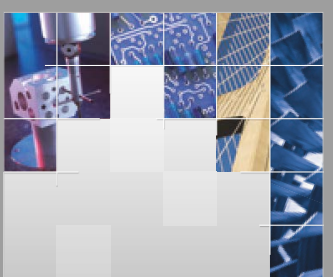

\section{Enfincering}
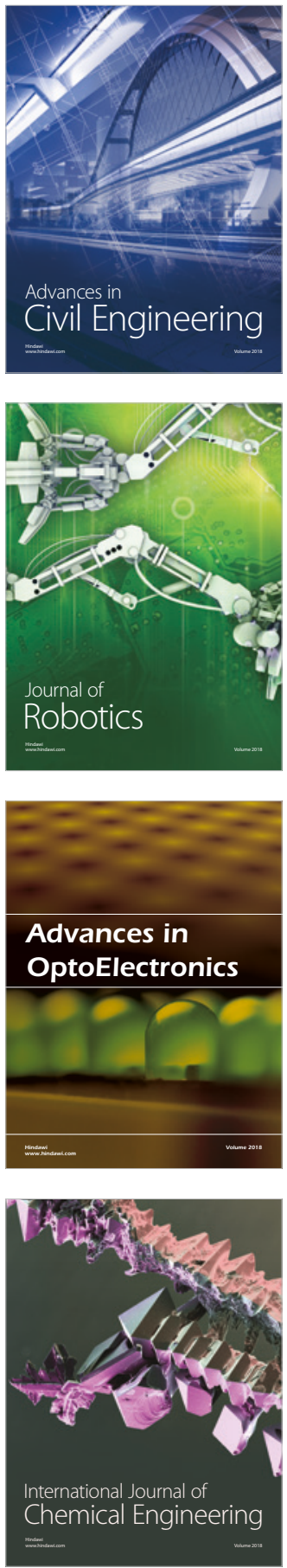

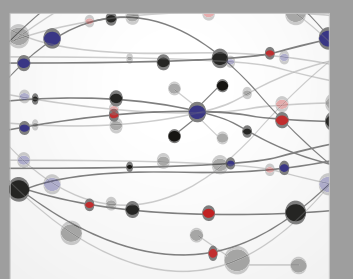

\section{Rotating \\ Machinery}

The Scientific World Journal

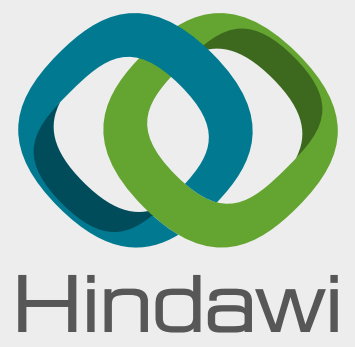

Submit your manuscripts at

www.hindawi.com
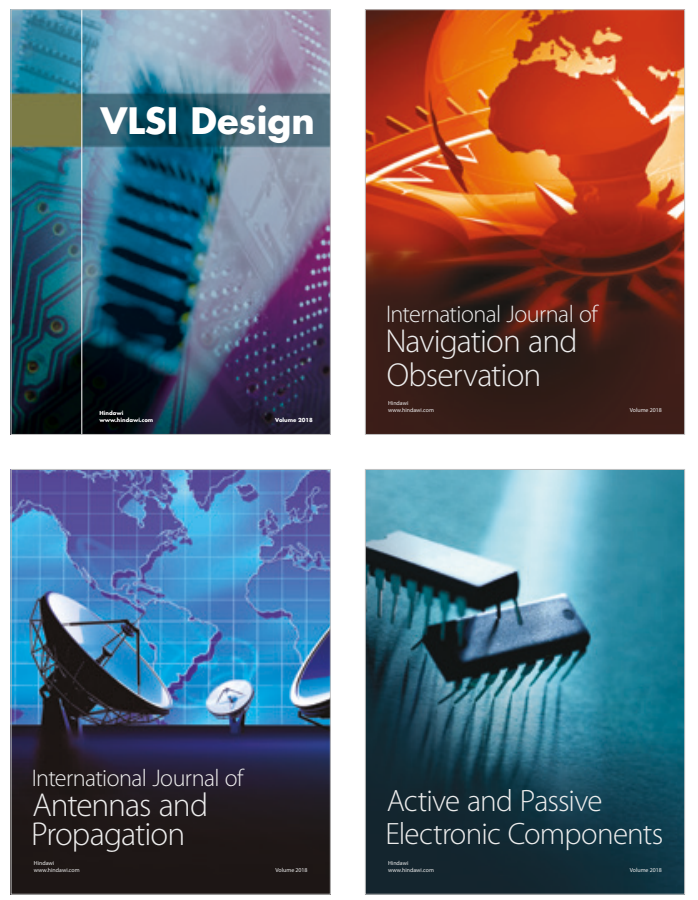
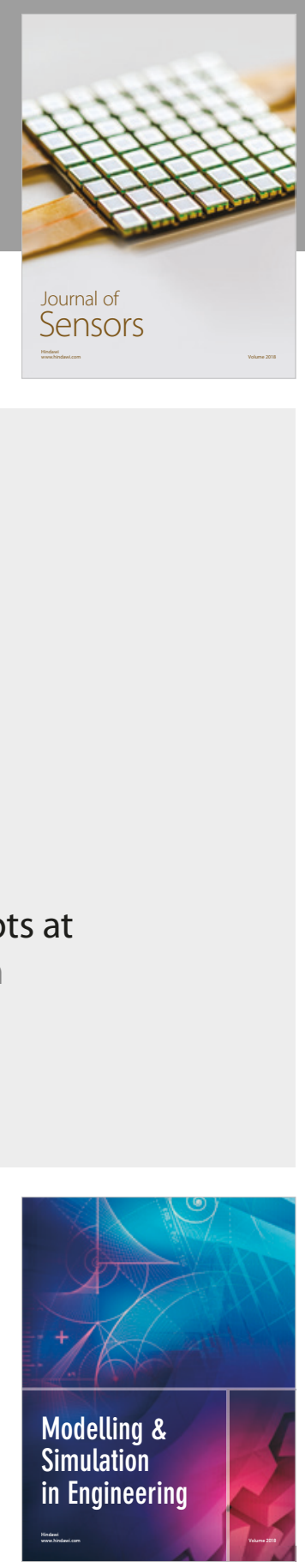

\section{Advances \\ Multimedia}
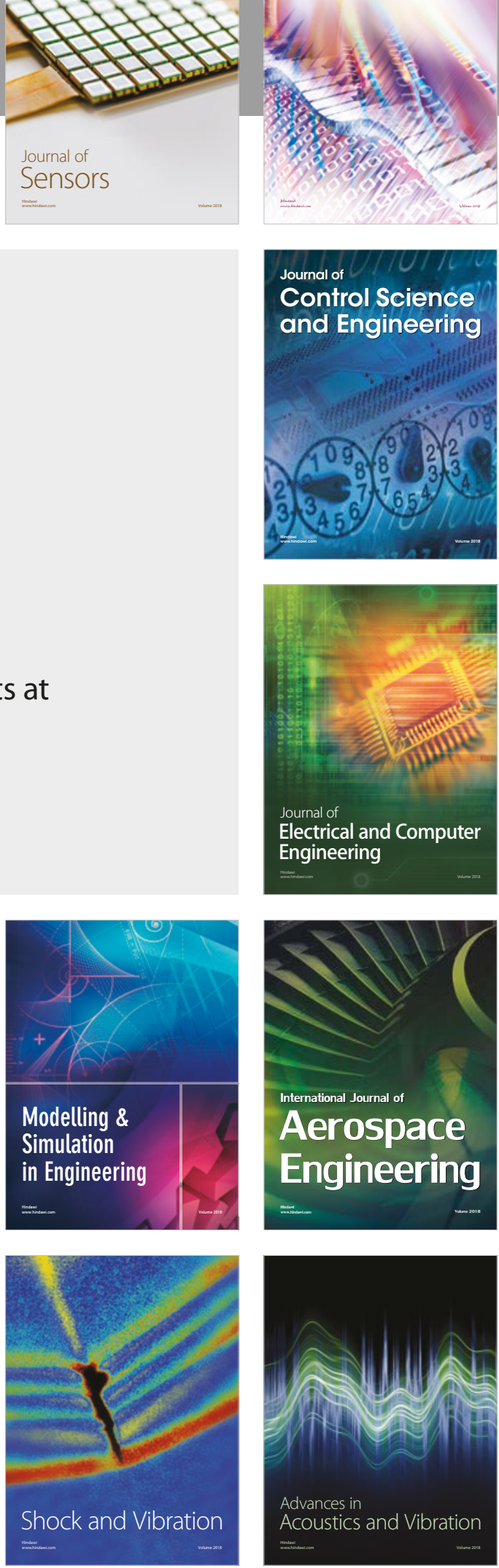